\title{
Las mariposas de Francisco José de Caldas y Thenorio
}

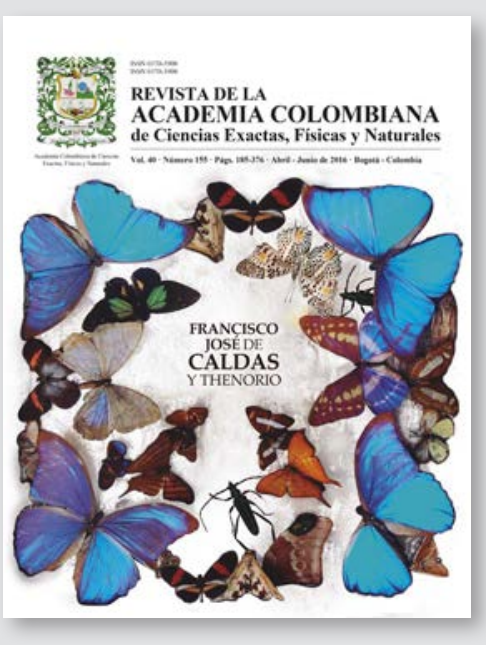

Jorge Reynolds Pombo es un enamorado de la naturaleza, de la vida y de la obra del sabio Caldas, su pariente por el lado Thenorio. Es esta la razón por la cual heredó de su madre, la señora Rosa Pombo de Reynolds, una colección de insectos y mariposas que pertenecieron a Francisco José de Caldas y Thenorio, razón por la cual, las conserva desde hace muchos años.

Lino de Pombo, pariente de Reynolds en sexta generación, nació en Cartagena, tuvo mucho que ver con Caldas, eran muy amigos y cuando se vino para Bogotá ya estaban planeando la forma de cómo sacar a los españoles del país. Rafael Pombo, probablemente conoció a Caldas pero fue de su padre de quien recibió mucha información. Rafael Pombo vivió casi 20 años en Nueva York y a su regreso, heredó una buena fortuna por lo que-se dedicó a comprarle a la gente objetos del sabio Caldas. De esta forma hizo una colección y dentro de lo comprado estaba su escritorio. A su muerte y puesto que Rafael era soltero, los recuerdos de Caldas se repartieron entre sus sobrinos nietos; uno de los cuales era Jorge Pombo, abuelo de Jorge quien había sido nombrado albacea de su testamento pero quien murió 8 días después de Rafael Pombo ya que durante los discursos en el cementerio desarrolló una pulmonía, y en esa época la pulmonía era prácticamente mortal. Fue entonces cuando nombraron a otra persona de la familia, en fin... por lo que finalmente la mamá de Jorge heredó el escritorio con sus cajas y todo.

Las cajas se encontraron en el escritorio del Sabio Caldas, que hoy es el escritorio de Jorge. La historia de todo esto comienza en la ciudad de Bogotá, en la casa de la carrera 13 con calle sexta, la casa donde él había nacido y como lo habían hecho otras cinco generaciones.

Frente a estas cajas, se resolvió que lo primero de todo sería realizar su limpieza, se procedió a abrirlas y a remover la enorme capa de polvo, a pesar de que se veían más o menos bien los colores, pero ya con la limpieza esto cambió totalmente, fueron como seis meses de este trabajo llevado a cabo una vez por semana.

Una de las cosas curiosas fueron los vidrios de las cajas, vidrios hechos a mano, en ese tiempo todavía no existían las máquinas para pulir y el tamaño de los vidrios era muy pequeño, además se anotaban las ondulaciones porque no eran totalmente planos. En una caja, Ángela Botero, esposa de Jorge, miró con cuidado y después de quitar la capa oscura que tenía encima, encontró un montón de arabescos dorados en todo el marco de las cajas, además y hasta donde era posible también se hizo una reconstrucción en el fondo de las cajas, las que tenía papel cromado (estaño), no se le quitó el papel cromado, sólo se arreglaron las cajas.

Alfredo Bateman nos contó en 1948 y 1952, Francisco José de Caldas nació en Popayán en el año de 1768, inició sus estudios en el seminario de su ciudad natal, en 1788 viajó a Santa Fe para continuar sus estudios en el Colegio Mayor del Nuestra señora del Rosario para viajar en 1801 a Quito, con el objeto de defender un pleito de su familia. Volvió ese mismo año hasta Ibarra (Ecuador) para encontrarse con Alexander von Humboldt, en cuya compañía hizo varias excursiones por los alrededores de Quito, y permanecieron 
juntos algún tiempo en los Chillos, casa de campo del Marqués de Selva Alegre. Los estudios que Caldas llevara a cabo durante sus viajes estaban enfocados a realizar observaciones con el barómetro, la brújula, y el termómetro; midió así la altitud de varios sitios, y fijó las coordenadas geográficas de muchos lugares; también experimentó para descubrir si un insecto era venenoso, entre otros interesantes temas.

Decidimos estudiar las dos cajas en el apartamento de Jorge, por dos razones: la primera por la importancia histórica que tenían estos insectos y segundo porque ese era el lugar donde éstas se encontraban, por lo que el trabajo de curaduría se realizó allá.

En las cajas de insectos de Caldas, encontramos mariposas, cucarrones, libélulas, polillas, abejas y avispas, las que se calcula llevaban más o menos unos doscientos años sin que tales cajas se abrieran por primera vez. Esto lo comprobamos porque en la base de las cajas no habían más agujeros producto de los alfileres que tenían los ejemplares para sujetarlos, Jorge narra "Me acuerdo que en mi casa durante toda la vida desde que yo estaba muy pequeño, ahí estaban los dos marcos, cuando las miraba mi mamá me decía: Estas cajas vienen por herencia del sabio Caldas, fue una colección que él hizo. - Cuando lo fusilaron, abrieron la casa, la gente entraba y cogían lo que quisieron, eso era: el motín de herencias “

Encontramos en total 106 insectos, divididos en dos cajas, una con 40 y la otra con 66. Los insectos se encontraban pinchados con un alfiler de la época, ya que su forma y textura no correspondían con los recientes por que los alfileres de ahora son los que se utilizan para la costura, no sirven para preservar insectos porque se oxidan muy rápido y esos alfileres tampoco eran entomológicos que están elaborados en acero inoxidable con cabeza de nylon.

Inicialmente le tomamos fotos a las dos cajas, antes de ser abiertas por primer vez, para después volver a dejar los insectos en sus lugares originales; así fue como nos dimos a la tarea de comenzar la limpieza de cada uno de los insectos, con mucho cuidado, primero utilizamos un pincel muy fino, para no quitarle las escamas a las mariposas; ya que las alas de las mariposas están cubiertas de unas escamas muy pequeñas.

El polvo que íbamos recolectando de los ejemplares fue guardado en un vial, algunas mariposas y demás insectos fueron soplados con aparatos de limpiar lentes de las cámaras de fotografía, los cucarrones, abejas fueron también limpiados con pincel y luego les dimos una baño con una solución contra hongos hasta lograr sus brillos naturales.

Actualmente continuamos con el estudio de estos insectos.

M. Gonzalo Andrade-C

Profesor Asociado

Curador colección de mariposas

Instituto de Ciencias Naturales, Universidad Nacional de Colombia

Miembro de Número, Academia Colombiana de Ciencias Exactas, Físicas y Naturales

La reproducción de la portada fue autorizada por los académicos Jorge Reynolds Pombo y M. Gonzalo Andrade-C 